\title{
Comparative Analysis of the Effect of Organoclay, Boron Nitride, and Fluoropolymer on the Rheology and Instabilities in the Extrusion of High Density Polyethylene
}

\author{
A. A. Adesina, ${ }^{1}$ M. S. Nasser, ${ }^{2}$ and I. A. Hussein ${ }^{1}$ \\ ${ }^{1}$ Department of Chemical Engineering, King Fahd University of Petroleum and Minerals, Dhahran 31261, Saudi Arabia \\ ${ }^{2}$ Gas Processing Center, College of Engineering, Qatar University, P.O. Box 2713, Doha, Qatar \\ Correspondence should be addressed to I. A. Hussein; ihussein@kfupm.edu.sa
}

Received 15 October 2014; Revised 8 February 2015; Accepted 9 February 2015

Academic Editor: Seyed-Hassan Jafari

Copyright ( 2015 A. A. Adesina et al. This is an open access article distributed under the Creative Commons Attribution License, which permits unrestricted use, distribution, and reproduction in any medium, provided the original work is properly cited.

\begin{abstract}
The effect of different processing additives on the extrusion instabilities of high density polyethylene (HDPE) was investigated. The concentration of each processing additive was fixed at $0.05 \mathrm{wt} \%$. Organoclay, boron nitride, and fluoropolymer reduced transient shear and extensional viscosities of HDPE melt. Drop in extrusion pressure occurred during the extrusion experiment. The initial loss of glossiness in HDPE was restored with the addition of these additives. However, the fluoropolymer did not succeed in eliminating the stick-slip fracture. Despite the inclusion of the processing additives, gross-melt fracture in HDPE reappeared at apparent shear rate of $141 \mathrm{~s}^{-1}$. Both moment and distortion factor methods of analyses were employed and their findings support the observed visual trends of the extrudate surface. The quantifying tools indicated that combined organoclay and fluoropolymer reduced the pressure fluctuations and its performance surpassed that of the individual additives.
\end{abstract}

\section{Introduction}

The major challenge during extrusion is the onset of melt instabilities that hinder high productivity [1-4]. Processing aids are often added to polyolefins during their extrusion to make the processes economically viable. With the addition of these additives, the processing window is expanded. The most common processing additive for polyolefin is fluoropolymer [5-14]. Stearates [15], silicon-based additives, hyperbranched polymers $[16,17]$, and blends of polymers $[18,19]$ are other forms of conventional processing aids. Another processing aid found useful in the elimination of gross-melt fracture is boron nitride [5, 20-22]. Recently, it was shown that organoclay is also a good candidate as a processing additive [2327]. There is a good review on the processing additives in [28].

Fluoropolymer is added to polyolefins either as an additive or as a coat on the die $[9,29-31]$ to increase the throughput of polyolefins. As an additive, fluoropolymer is added in small quantity less than $0.1 \mathrm{wt} \%$. Due to its high incompatibility with polyolefins, a two-phase blend is formed during extrusion. As a result, master batch-dilution mode of preparation is often adopted in the preparation of the blend. Fluoropolymer thus promotes wall slip due to its strong interaction with the die wall $[7,9,11,12,32]$. The interaction was reported to occur due to cohesive failure [11] or adhesive failure $[6,33,34]$. The flow curve of HDPE shifted to higher shear rates in the presence of fluoroelastomer [5] in an extrusion through a capillary rheometer. Fluoropolymer was suggested to have eliminated both sharkskin and stick-slip instability in several polyolefins $[5,8,13,35,36]$. Furthermore, fluoropolymer reduced the extrusion pressure (shear stress) by coating the die entrance of the die and then migrating as streaks to the die exit where the sharkskin is eliminated [10]. The coating time reduced with increasing fluoropolymer concentration. However, excessive amount of fluoropolymer could lead to excessive lubrication of the extruder barrel, hence undesired effects [28]. In addition, fluoropolymer enhances other properties in polyolefins. For example, the fluoropolymer-induced slip could lead to a decrease in the shear stress in the bulk and hence increases the draw ratio and melt strength during stretching [7]. The addition of fluoropolymer could as well lead to gel reduction, reduced die build up and elimination of 
draw resonance in film casting [28]. However, fluoropolymer did not eliminate gross-melt fracture.

As a processing aid, a very small amount of boron nitride (typically less than $0.5 \mathrm{wt} \%$ ) is added to polyolefin. It was reported that such small amount of boron nitride has no effect on the linear and nonlinear viscoelastic properties of polyethylenes [20,37]. However, boron nitride slowed down the relaxation of metallocene polyethylenes during "relaxation after cessation of steady shear" (at shear rate of $1 \mathrm{~s}^{-1}$ ) but disappeared at higher shear rates [20, 28]. Also, boron nitride was suggested to eliminate surface melt fracture and postpone gross-melt fracture at high shear rates in metallocene polyethylenes [20] and HDPE [37]. Similar to fluoropolymer, it was proposed that boron nitride migrates to the surface of the die especially at the die exit hence stick-slip is eliminated [37]. Boron nitride was reported to eliminate the gross-melt fracture in polypropylene by making the discontinuous streamlines in the polymer bulk flow smoother at the die entry [21]. The authors concluded that it has no effect on the flow curve of polyethylene in capillary flow [20] but a small decrease in extrusion pressure may occur [37]. The effectiveness of boron nitride is dependent on its concentration in polyethylenes. Generally, a concentration less than $0.1 \mathrm{wt} \%$ was suggested to work better in polyethylenes [20, 37, 38]. Extrusion temperature, induction time, particle size, and dispersion of boron nitride in the polymer matrix and its surface energy were important factors in the elimination of gross-melt fracture by boron nitride $[37,39]$. Boron nitride is also used as a processing aid in other polymer processing applications such as film blowing [40] and melt spinning [41].

In the case of organoclay, a very small amount was suggested for use (less than $0.5 \mathrm{wt} \%$ ) in polyolefin processing [42]. The organoclay affected both the linear and nonlinear rheology of HDPE [42, 43]. However, its effect decreases as the branch content of the polyethylene increases [43]. Organoclay was recently reported to be effective in the elimination of surface melt fracture and postponement of gross-melt fracture to higher shear rates [36, 43].

Fluoropolymer and boron nitride were combined to enhance and expand the processing window of polyolefins. The onset of gross-melt fracture and reduction of extrusion pressure can further be enhanced when the processing aids were used individually $[20,37,41,44]$. To the best knowledge of the authors, only few researchers explored the impact and performance of different nanoadditives [23].

In this paper, boron nitride, organoclay, fluoropolymer, and the combination of fluoropolymer and organoclay were used as processing aids in the extrusion of HDPE. The concentration of each additive was fixed at $0.05 \mathrm{wt} \%$. As previously shown in our work [42], $0.05 \mathrm{wt} \%$ of organoclay performed better than $0.1 \mathrm{wt} \%$. It was shown that agglomeration might be more in the latter. For fair comparison of all the additives, the concentration of each additive was kept constant at $0.05 \mathrm{wt} \%$. A specially designed slit die containing three highly sensitive pressure transducers was used for monitoring pressure fluctuations in a slit die. The slit die was attached to a single screw extruder. The recorded fluctuations at different flow regimes were analyzed for the identification of the effectiveness of the individual and mixed additives. To the best knowledge of the authors, such fluctuations were for first time quantified using moment and Fourier transform methods of analyses.

\section{Experimental}

2.1. Materials. Commercial grade HDPE (relative density $=0.952$, melting point $=132^{\circ} \mathrm{C}$, and melt flow index $=$ $0.05 \mathrm{~g} / 10 \mathrm{mins}$ at $190^{\circ} \mathrm{C}$ and $2.16 \mathrm{~kg}$ load) was used in this research. Its average weight, molecular weight $\left(M_{w}\right)$, and polydispersity index (PDI) were $285 \mathrm{~kg} / \mathrm{mol}$ and 26.5, respectively. The organoclay used in this research was Cloisite $15 \mathrm{~A}$ (C15A) from Southern Clay, USA. According to the supplier, the $\mathrm{d}_{001}$ spacing of C15A was 31.5 Angstrom. Boron nitride contained $0.2 \%$ borates. It had mean diameter less than $1 \mu \mathrm{m}$ and surface area of $20 \mathrm{~m}^{2} / \mathrm{g}$ and was supplied by Saint-Gobain Ceramics, USA. Dynamar, a free-flowing fluoropolymer from Dyneon, USA, was used to represent a conventional processing additive. It is a copolymer of hexafluoropropylene (HFP), vinylidene fluoride $\left(\mathrm{VF}_{2}\right)$, and tetrafluoroethylene (TFE). It has bulk density of 0.7 . Antioxidant $(0.1 \mathrm{wt} \%)$ was added to all samples to avoid degradation during melt blending [43]. It is a 50/50 weight blend of Irganox 1010 and Irgafos 168 from Ciba-Geigy Speciality, Switzerland.

2.2. Melt Blending and Morphology Characterization. Brabender 50 EHT mixer supplied with a Plastograph (Brabender $\mathrm{GmbH} \& \mathrm{Co}$., Germany) was used in the preparation of the nanocomposites. Details of pretreatment of C15A were given elsewhere [42]. Boron nitride and Dynamar were used as received from the manufacturers. HDPE was grinded and physically premixed with each processing additive. Antioxidant was added during the physical mixing. Then, master batches containing organoclay and boron nitride were prepared in the Brabender mixer. A desired final concentration of a particular blend was obtained by mixing additional virgin HDPE with the master batch using the same mixer. The blending was done at a temperature of $200^{\circ} \mathrm{C}$ and a screw speed of $50 \mathrm{rpm}$ for 10 minutes.

The amount of each processing aid was fixed to $0.05 \mathrm{wt} \%$. To study the synergistic effect between organoclay and conventional processing additive, a final batch containing $0.05 \mathrm{wt} \%$ of $\mathrm{C} 15 \mathrm{~A}$ and $0.05 \mathrm{wt} \%$ Dynamar was prepared. In this research, HDPE-C15A, HDPE-BN, and HDPE-C15AFluoro (HDPE mixed with $\mathrm{C} 15 \mathrm{~A}$ and Dynamar) indicate that HDPE containing $0.05 \mathrm{wt} \% \mathrm{C} 15 \mathrm{~A}, 0.05 \mathrm{wt} \%$ boron nitride, and $0.05 \mathrm{wt} \% \mathrm{C} 15 \mathrm{~A}+0.05 \mathrm{wt} \%$ Dynamar fluoropolymer were used, respectively.

The structures of the (nano-) composites were characterized by field emission scanning electron microscopy (FESEM) and X-ray diffractometry (XRD). The XRD analysis was performed on XRD-6000 Shimadzu diffractometer (Shimadzu, Japan) with $\mathrm{CuK} \alpha$ radiation $(\lambda=0.154 \mathrm{~nm})$ in a reflection mode, operating at $40 \mathrm{kV}$ and $30 \mathrm{~mA}$. Scanning speed of $1^{\circ} / \mathrm{min}$ was used. The scan range was $2-20^{\circ}$ at room temperature. Scanning electron micrographs were obtained with FE-SEM Nova Nanosem 230 (FEI, USA). It was possible to achieve ultra-high resolution on nonconductive nanomaterials with Nova Nanosem 230. The SEM samples were made 
into thin films and etched for 4 hours. The etching solution is a solution of $\mathrm{H}_{2} \mathrm{SO}_{4} / \mathrm{H}_{3} \mathrm{PO}_{4} / \mathrm{H}_{2} \mathrm{O}(10 / 4 / 1)$ and $0.01 \mathrm{~g} / \mathrm{mL}$ $\mathrm{KMnO}_{4}$. The etched samples were further covered with gold to make them conductive.

2.3. Rheological Measurement. The samples for the shear and extensional experiments were prepared from melt blended samples using a Carver press at a temperature of $200^{\circ} \mathrm{C}$. The disc samples with dimensions of $25 \mathrm{~mm}$ diameter and $2 \mathrm{~mm}$ thickness were prepared for shear rheology. The final dimensions of the solid polymer specimens for extensional tests were approximately $17 \mathrm{~mm}$ in length and $10.0 \mathrm{~mm}$ in width, with thicknesses in the range of $0.70-1.0 \mathrm{~mm}$.

ARES rheometer (TA Instruments, USA) was used for all the rheological measurements. The plates were heated for at least 20 minutes to equilibrate the temperature. Strain sweep tests were conducted for all the samples to determine the linear viscoelastic region and for Fourier transform rheology (FT-rheology). A Strain range of $10-400 \%$ with shear amplitude of $1 \mathrm{rad} / \mathrm{s}$ was used. The details on the FT-rheology were given in a previous publication [43]. Frequency sweep experiments at $200^{\circ} \mathrm{C}$ were performed in the frequency range between $0.01 \mathrm{rad} / \mathrm{s}$ and $100 \mathrm{rad} / \mathrm{s}$. The applied strain was $10 \%$. Van Gurp Palmen plots $\left[\delta\left(\arctan G^{\prime \prime} / G^{\prime}\right)\right.$ versus complex modulus $G^{*}$ ] were drawn from the frequency sweep data.

It has been shown that that the shear stress response involves harmonics. The intensities and phases of such harmonics were used in the characterization of nonlinearity in the polymer. Most importantly the relative intensity of the third harmonic $\left(I_{3 / 1}\right)$ and relative phase angle of the third harmonic $\left(\Phi_{3}\right)$ were found to be very useful in such analysis $[2,42]$. They were defined as

$$
\begin{gathered}
I_{3 / 1}=\frac{I\left(3 w_{1}\right)}{I\left(w_{1}\right)}, \\
\Phi_{3}=\varphi_{3}-\varphi_{1},
\end{gathered}
$$

where $I\left(3 w_{1}\right)$ and $\varphi_{3}$ are the shear stress intensity of the third harmonics and phase angle of the third harmonic, respectively. $I\left(w_{1}\right)$ and $\varphi_{1}$ are the shear stress intensity and phase angle of the first harmonic, respectively. Most of the experiments were repeated three times. The maximum deviation in $I_{3 / 1}$ and $I_{2 / 1}$ were found to be less than $5 \%$ of the mean and less than $\pm 5^{\circ}$ around the mean for $\Phi_{3}$.

Most of the experiments were repeated three times with maximum deviation less than $5 \%$ from the mean. The responses of the samples during stress growth at $200^{\circ} \mathrm{C}$ were conducted to study the effect of organoclay on the nonlinear shear material function of HDPE. The imposed shear rate was $0.8 \mathrm{~s}^{-1}$. Low shear rate was used due to the limitation of the parallel plate geometry. The results were reproducible with maximum deviation of $10 \%$ around the mean.

Extensional viscosity fixture (EVF) from TA Instruments was used for the study of extensional rheology. The samples were prestretched with a strain rate of $0.4 \mathrm{~s}^{-1}$ to remove sagging. The sample was left in the fixture for 3 minutes to relax any accumulated stress before the start of the experiment. A Hencky strain rate of $10 \mathrm{~s}^{-1}$ at a temperature of $145^{\circ} \mathrm{C}$ was used during the extensional experiments. Such a high Hencky strain rate and low temperature were necessary to observe the effect of the processing additives on the extensional rheology of HDPE. The results were reproducible with maximum deviation of $10 \%$ around the mean.

2.4. Setup for Melt Flow Instabilities and Extrusion Pressure. Extrusion was carried out in a single screw extruder 19/25D (Brabender GmbH \& Co., Germany) equipped with a specially developed slit die. The slit die had dimensions of $0.8 \mathrm{~mm}$ height, $20 \mathrm{~mm}$ width, and $160 \mathrm{~mm}$ length. The slit die has three highly sensitive piezoelectric transducers located at $30 \mathrm{~mm}, 80 \mathrm{~mm}$, and $140 \mathrm{~mm}$ from the entrance of the die. The pressure and time resolutions of these transducers are of the order $10^{-1}$ mbar and $1 \mathrm{~ms}$, respectively. Details about the setup were shown elsewhere [43]. The temperature of the three heater bands along the extruder was $180^{\circ} \mathrm{C}$ while the temperature of the die was $170^{\circ} \mathrm{C}$. The measurements with the three highly sensitive piezoelectric transducers were done to specifically identify and analyze the time dependent pressure fluctuations associated with smooth polymer flow and melt flow instabilities. The time dependent pressure oscillations were collected by the use of these fast acquisition piezoelectric transducers combined with an oversampling technique to increase the noise to signal ratio. So, the 30,000 data points/channel were reduced to 100 data points/s using an oversampling rate of 300 data points/s.

The pressure fluctuations from piezoelectric transducers were further analyzed using second-order moment and Fourier transform analyses as defined in the following equation and (3), respectively:

$$
m_{2}=\frac{1}{t_{f}-t_{o}} \int_{t_{o}}^{t_{f}}(p(t)-\bar{p})^{2} d t
$$

where $m_{2}$ is the second moment of the pressure, $\bar{p}$ is the mean value which is the first moment around zero, and $p(t)$ is the time dependent pressure fluctuation signal. The second moment is the variance and its square root is the standard deviation. In this work, the ratio of the standard deviation divided by the mean of the pressure fluctuation was used in the characterization of the melt instability. Consider

$$
p(t)=\bar{p}+\sum_{i \geq 1} l_{i} \cos \left(w_{i} t+\phi_{i}\right)
$$

where $\bar{p}$ is the pressure mean value at $w / 2 \pi=0 ; w_{i} / 2 \pi, \phi_{i}$, and $l_{i}$ are the characteristic frequencies, phases, and amplitudes of the pressure fluctuation as quantified from the Fourier analysis of the processed signals, respectively. One of the most important parameters from the FT analysis in quantifying melt instabilities is the distortion factor (DF). This is a measure of the relative pressure fluctuation (RPF) as defined below:

$$
\mathrm{DF}=\frac{\sum_{i \geq 1} l_{i}}{l_{0}},
$$

where $l_{0}$ is the peak value at $w=0$ and it is related to the pressure mean value. 


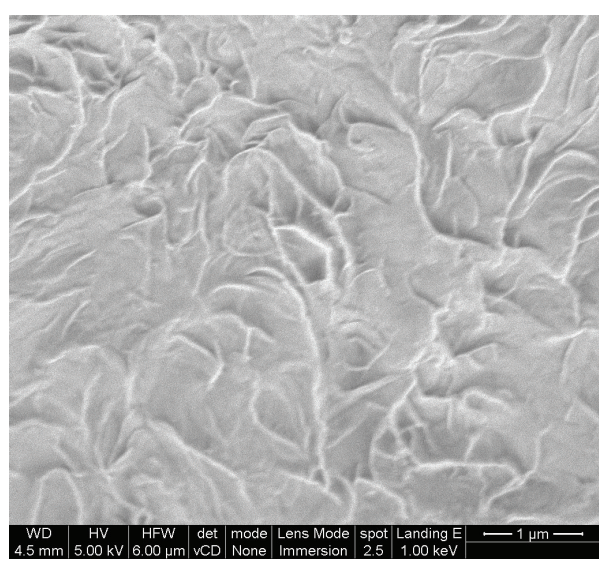

(a)

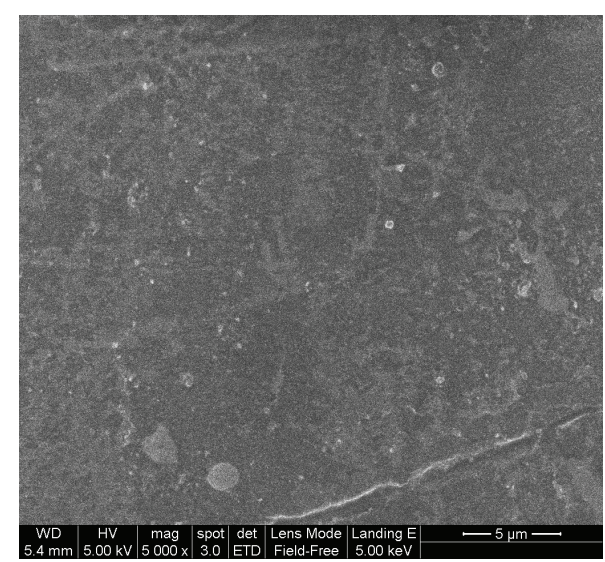

(b)

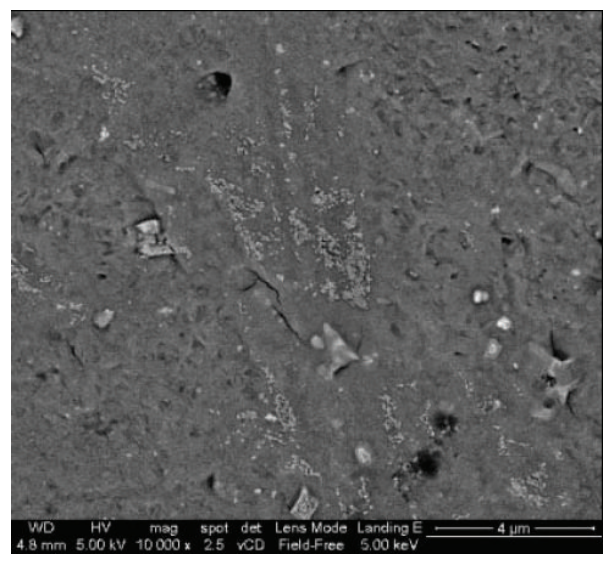

(c)

FIgure 1: SEM of (a) Pure HPDE, (b) HDPE-C15A, and (c) HDPE-BN.

The pressure drop $(\Delta P)$ across the slit die was measured with the Dynisco pressure transducer placed at the entrance of the slit die. The acquisition rate was 1 data per $20 \mathrm{~s}$.

The volumetric flow rate $(\dot{Q})$ was determined by collecting and measuring the ejected mass as a function of time. From the data, the wall shear stress $\left(\tau_{\text {app }}\right)$ and the apparent shear rate $\left(\hat{\gamma}_{\text {app }}^{\bullet}\right)$ were calculated using

$$
\begin{gathered}
\tau_{\text {app }}=\Delta P \frac{h}{2 l}, \\
\gamma_{\text {app }}=6 \frac{\dot{Q}}{b h^{2}},
\end{gathered}
$$

where, $h, l$, and $b$ are the height, length, and width of the slit die, respectively.

Further, continuous MiniLab II Haake Rheomex CTW5 was used to study the effect of the additives on extrusion pressure of HDPE at high shear rates compared to that obtained in Brabender single screw extruder. The tests were conducted at $170^{\circ} \mathrm{C}$. The MiniLab consists of 5/14 diameter conical counter rotating twin screw extruder with backflow channel. The backflow channel was designed as a slit capillary $(64 \mathrm{~mm} \times 10 \mathrm{~mm} \times 1.5 \mathrm{~mm})$ with two pressure transducers at the capillary entrance and exit. Samples were fed into the MiniLab in 3 steps with 2-3 mL of the sample fed-in during each step. As found in this work, the results were reproducible with a maximum deviation of $\pm 4 \%$ around the mean for all the allowable shear rates.

\section{Results and Discussion}

3.1. Morphological Characterization. The SEM of pure HDPE, HDPE-C15A, and HDPE-BN was as shown in Figure 1. Figure 1(a) shows HDPE without any additives. Figure 1(b) shows organoclay as dispersed in the HDPE matrix. However, the dispersion of boron nitride is accompanied with its agglomeration as shown in Figure 1(c). The low distributive shearing effect of the mixer might has contributed to the agglomeration despite the residence time of 10 minutes.

3.2. Rheological Characterization. The frequency sweep data for each sample was presented in the form of van Gurp Palmen curve as shown in Figure 2. At the crossover region of the plot, no difference was observed in the phase angle. However, below the crossover frequency, the HDPE curve had the least slope. The observed increment in the phase angle for both HDPE-C15A and HDPE-BN was similar. The 


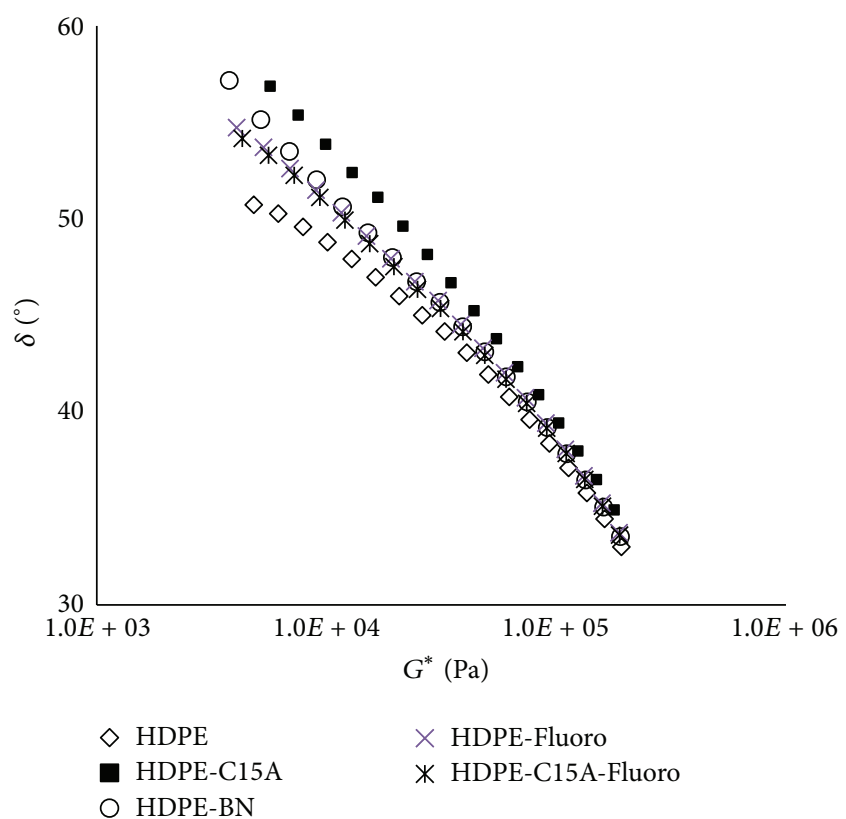

Figure 2: Van Gurp Palmen plot for HDPE, HDPE-C15A, HDPEBN, HDPE-Fluoro, and HDPE-C15A-Fluoro.

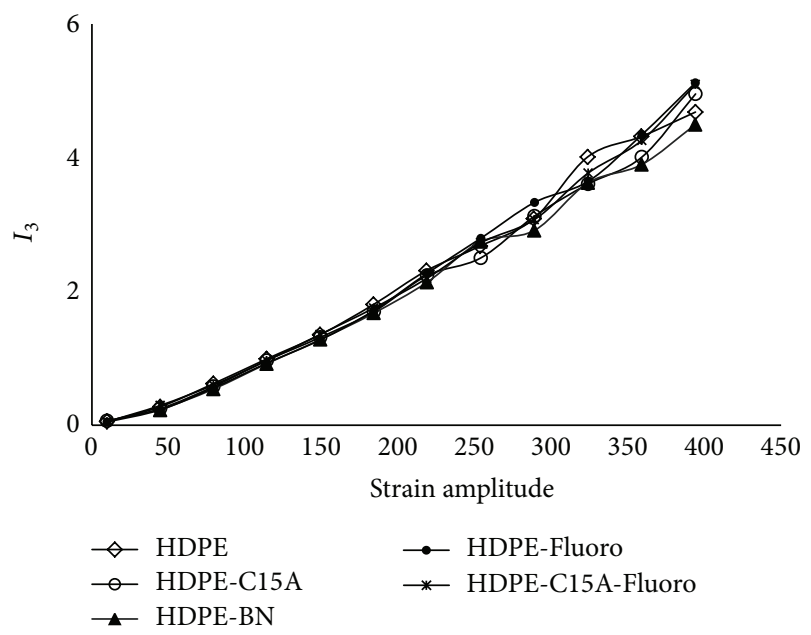

FIGURE 3: Relative intensity of the third harmonic as a function of strain amplitude at $200^{\circ} \mathrm{C}$ for HDPE, HDPE-C15A, HDPE-BN, HDPE-Fluoro, and HDPE-C15A-Fluoro.

blend of fluoropolymer and HDPE also resulted in increase in the phase angle of HDPE. The curve of HDPE-C15AFluoro was not different from that of HDPE-Fluoro. So, the three processing additives gave higher phase angle below the longest crossover frequency. This implies that all additives turn HDPE melt to be more viscous or less elastic.

Figures 3 and 4 show the relative intensity and phase angle of the third harmonic of all the samples, respectively. The FT-rheology did not show the effect of processing additives on HDPE. Thus, the impact of processing additives on the higher harmonics, including the third harmonics, is negligible. Figure 5 shows the effect of different processing

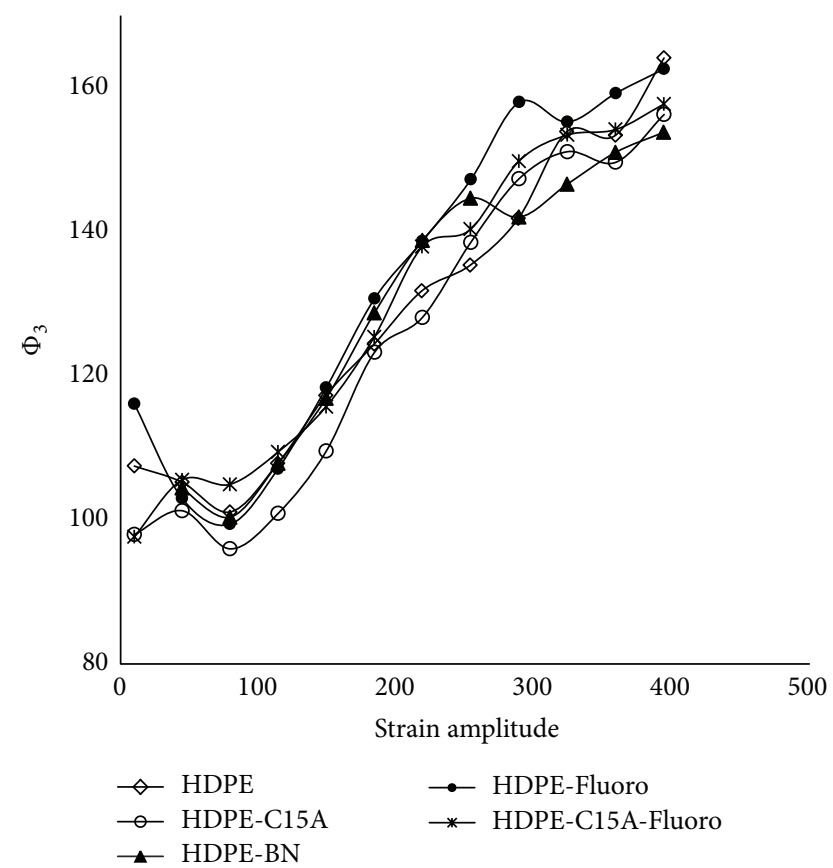

FIGURE 4: Relative phase angle of the third harmonic as a function of strain amplitude at $200^{\circ} \mathrm{C}$ for HDPE, HDPE-C15A, HDPE-BN, HDPE-Fluoro, and HDPE-C15A-Fluoro.

additives on HDPE during transient shear rheology. It can be seen that all the additives resulted in the reduction of the transient shear viscosity of HDPE. The highest reduction in the transient viscosity of HDPE occurred with the addition of $0.05 \mathrm{wt} \%$ organoclay. The addition of both organoclay and fluoropolymer in HDPE resulted in a decrease in the transient viscosity of HDPE as well (figure not shown).

The same trend was observed in the previous results of shear rheology (van Gurp Palmen plot), even though, not as obvious as observed during transient shear test experiment. Figure 6 shows the extensional test results for HDPE, HDPEC15A, HDPE-BN, and HDPE-Fluoro. The trend was similar to the results discussed during the transient shear growth stress. All displayed processing additives reduced the extensional stress in HDPE. The highest reduction was observed with the addition of $0.05 \mathrm{wt} \%$ organoclay. The extensional strain in HDPE was reduced as well in the presence of all processing additives.

3.3. Extrusion of HDPE with/without Processing Additives. Figure 7 shows the flow curve for the extrusion of HDPE with/without different additives in the continuous MiniLab. It is clear that adding the additives resulted in the drop of the extrusion pressure. The remarkable observation in the flow curve is the synergistic effect between organoclay and fluoropolymer. Three different flow regimes were observed in Brabender single screw extruder: smooth, stick-slip, and gross-melt fracture regimes. However, towards the end of the smooth regime the surface of the polymer melts slightly loses its glossiness as shown in Figure 8(b). Figure 8(a) is a typical visualized extrudate before the onset of loss of glossiness at the smooth regime. 


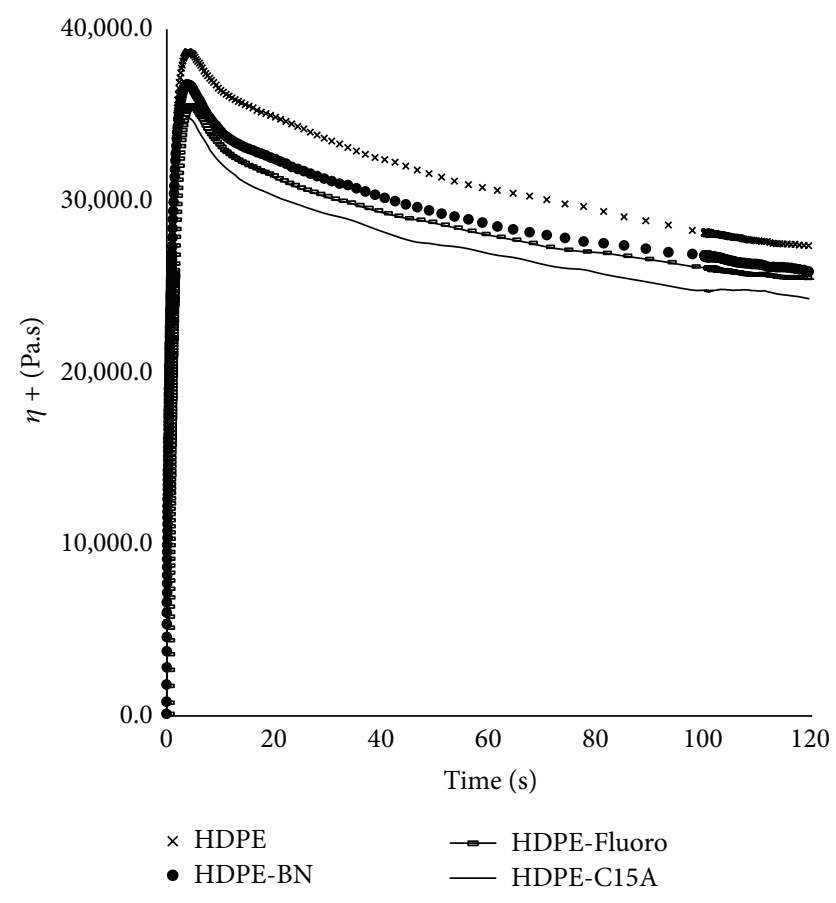

Figure 5: Transient shear growth test for HDPE, HDPE-C15A, HDPE-BN, and HDPE-Fluoro.

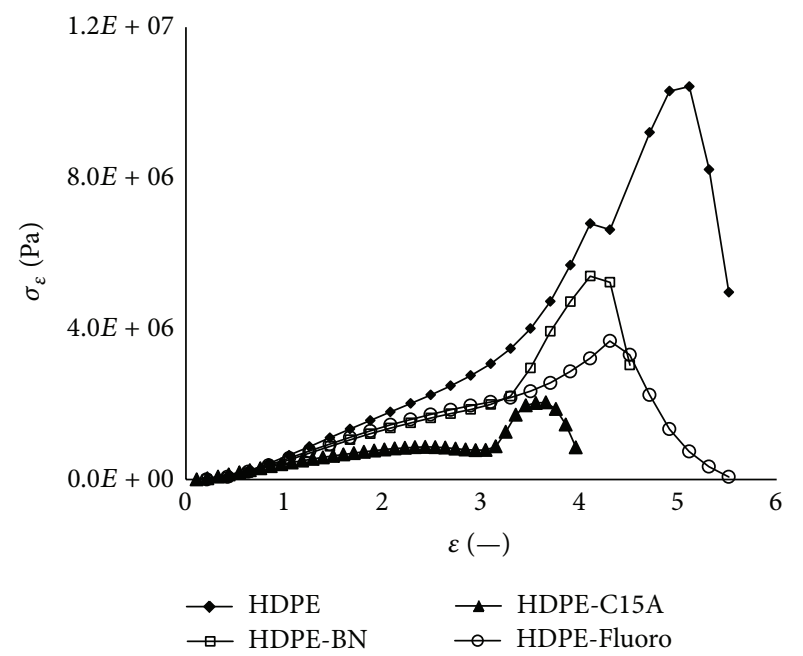

FIGURE 6: Extensional stress growth versus extensional strain for HDPE, HDPE-C15A, HDPE-BN, and HDPE-Fluoro.

Figure 9 shows the extrudate at the stick-slip and grossmelt fracture regimes. The stick-slip is characterized by high pressure fluctuations and high mean pressure. However, a pressure drop occurred at the onset of gross-melt fracture before gradual increase in the pressure (figure not shown).

The effect of the different processing aids on HDPE was studied at three apparent shear rates. The shear rates were selected from the three regions. This was done because of material consumption during the experiment. At each shear rate, the experiment was conducted to last for about 30 minutes to attain stable flow and collect data for Fourier

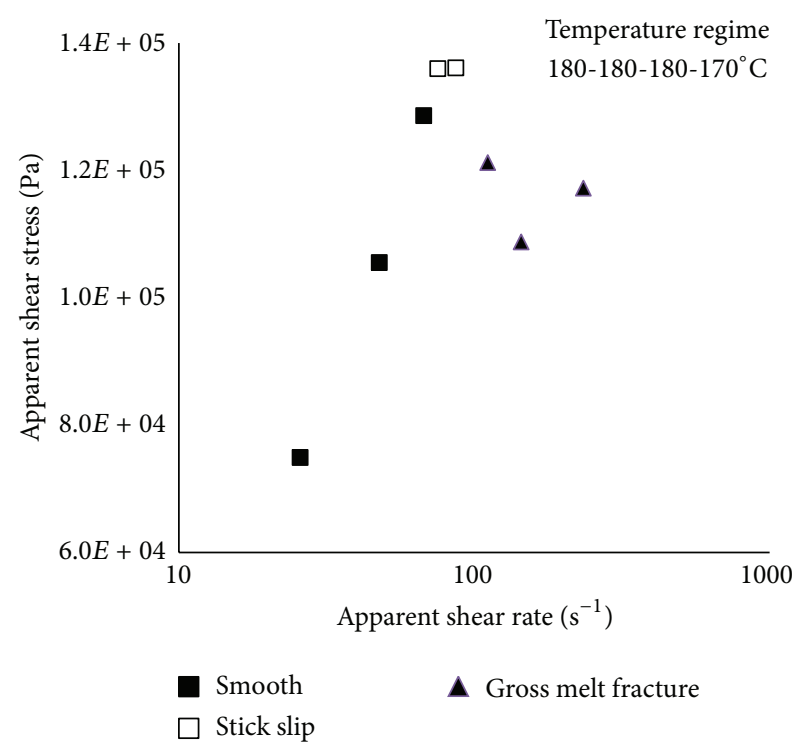

FIGURE 7: Flow curve of HDPE with and without additives at temperature $170^{\circ} \mathrm{C}$ in a MiniLab.

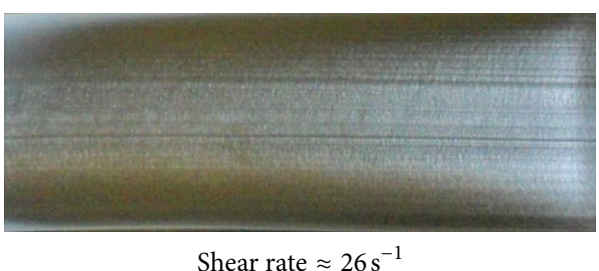

(a)

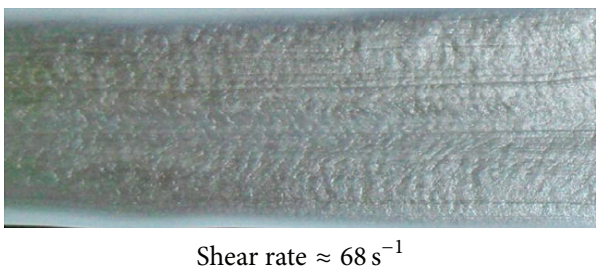

(b)

FIGURE 8: HDPE extrudate at a shear rate of $26 \mathrm{~s}^{-1}$ and (b) at a shear rate of $68 \mathrm{~s}^{-1}$.

transform analysis. The addition of the processing additives had effect on the appearance of the HDPE extrudate. It was visually observed that all the processing additives made the HDPE extrudate smoother at apparent shear rate of $67 \mathrm{~s}^{-1}$.

At apparent shear rate of $87 \mathrm{~s}^{-1}$ (stick slip regime), all the processing aids eliminated the stick-slip instabilities in HDPE except when the fluoropolymer was used alone. It was observed that the addition of fluoropolymer resulted in a smooth surface up to 15 minutes of extrusion, when the instability reappeared. At this time, the melt instability was not stick-slip but gross-melt fracture. The reason for the reappearance of the fracture might be due to the fact that the fluoropolymer concentration used in this work was not optimal. Figure 10(a) shows a typical result for all other processing 


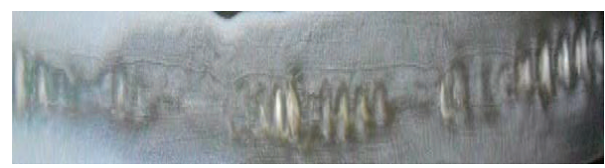

Shear rate $\approx 87 \mathrm{~s}^{-1}$

(a)

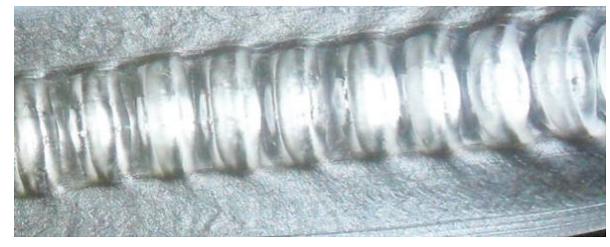

Shear rate $\approx 144 \mathrm{~s}^{-1}$

(b)

FIGURE 9: HDPE extrudate at a shear rate of $87 \mathrm{~s}^{-1}$ (stick-slip region) and (b) at a shear rate of $144 \mathrm{~s}^{-1}$ (gross-melt fracture region).

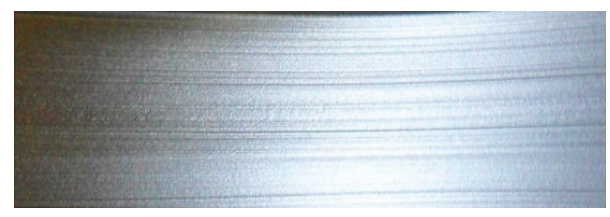

Shear rate $\approx 87 \mathrm{~s}^{-1}$

(a)

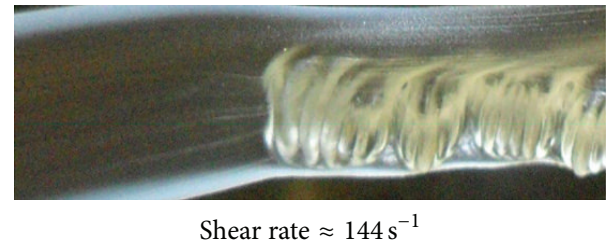

(b)

Figure 10: Extrudate of HDPE-C15A at apparent shear rate of (a) $87 \mathrm{~s}^{-1}$ (stick-slip region) and (b) $144 \mathrm{~s}^{-1}$ (gross-melt fracture region).

additives. At a given temperature, the onset of sharkskin depends on the composition and types of additive. For pure HDPE it was observed at $68 \mathrm{~s}^{-1}$ while the same onset shifted to a value between 87 and $144 \mathrm{~s}^{-1}$.

At apparent shear rate of $144 \mathrm{~s}^{-1}$, none of the processing additives eliminated the gross-melt fracture. The extrusion line was purged with pure HDPE before the commencement of any extrusion involving additives. At the beginning of the extrusion when the shear rate was $144 \mathrm{~s}^{-1}$, the extrudates were smooth but the melt instability set in after a period of time. The time before the onset of the gross-melt fracture varied depending on the additives. When the organoclay and fluoropolymer were combined together, it took about 20 minutes before the onset of the gross-melt fracture. This was found to be the longest time for all additives covered in this study. Figure 10(b) shows HDPE-C15A extrudate after about 8 minutes from the beginning of the experiment.

Figures 11 to 13 show the pressure fluctuations along the die characterized with moment and Fourier transform analyses. Figure 11 indicates that the pressure fluctuation of HDPE is the highest at apparent shear rate of $67 \mathrm{~s}^{-1}$. This result supports the visual images presented earlier in Figure 8 (b). At apparent shear rate of $87 \mathrm{~s}^{-1}$, all samples showed similar values of moment and DF except HDPE-Fluoro-C15A (Figure 11(a)) and HDPE-BN (Figure 11(b)).

As the polymer melt flew down the slit die, all samples except HDPE-Fluoro relaxed faster than HDPE. As a result, the fluctuations in HDPE-BN, HDPE-C15A, and HDPEFluoro-C15A were less as shown in Figures 12 and 13. These results also confirm the visual observations at stick-slip regime when all the additives remove the stick-slip instability except fluoropolymer. It is worthy of mentioning that the observed improvement during the extrusion of HDPE was due to the effect of the additives and not degradation due to processing. This was confirmed by conducting further dynamic frequency sweeps on the extrudates. The elastic and loss moduli of the samples before and after extrusion were found to be the same within the allowable error margins, which were less than $3 \%$. With increasing shear rate from 87 to 144 (see Figures 12 and 13), DF and SD/P decrease although gross-melt fracture occurs. Our proposed explanation for this observation is that the impact of processing aid additives is observed at higher shear rates where more instabilities take place. $\mathrm{SD} / P$ and $\mathrm{DF}$ represent deviations from a fixed value and these deviations are reduced at higher shear rates since the impact of additives on reducing the instabilities is enhanced.

At apparent shear rate of $141 \mathrm{~s}^{-1}$, the difference between the moment and DF analyses of all the samples was insignificant. This is in agreement with the observation that none of the processing additives eliminated the gross-melt fracture at this apparent shear rate. There is a need for further optimization with respect to the concentration of the processing aid. The addition of fluoropolymer to HDPE containing organoclay (HDPE-C15A-Fluoro) further reduced the DF and $\mathrm{SD} / P_{\text {mean }}$ of HDPE-C15A as shown in Figures 12 and 13.

\section{Conclusions}

The effect of different additives on the rheology and instabilities in the extrusion of HDPE was studied. It was found that organoclay, boron nitride, and fluoropolymer had effect on the phase angle of HDPE below the crossover frequency and the elastic modulus was reduced. Despite the effect of the additives on the phase angle of HDPE, the additives had no effect on the higher harmonics of HDPE as shown by FT-rheology. Organoclay, boron nitride, and fluoropolymer reduced the transient shear viscosity and extensional stress growth of HDPE. Furthermore, addition of fluoropolymer to HDPE containing organoclay reduced the transient shear viscosity and extensional stress growth. The rheological tool was not strong enough to clearly differentiate the potency of each additive on HDPE. This is due to the very low concentration of the processing aids. However, since these additives have effects on the shear and extensional rheology of HDPE, it is not surprising that they positively impact HDPE during its extrusion. Addition of fluoropolymer to organoclay reduced extrusion pressure. The observed surface 


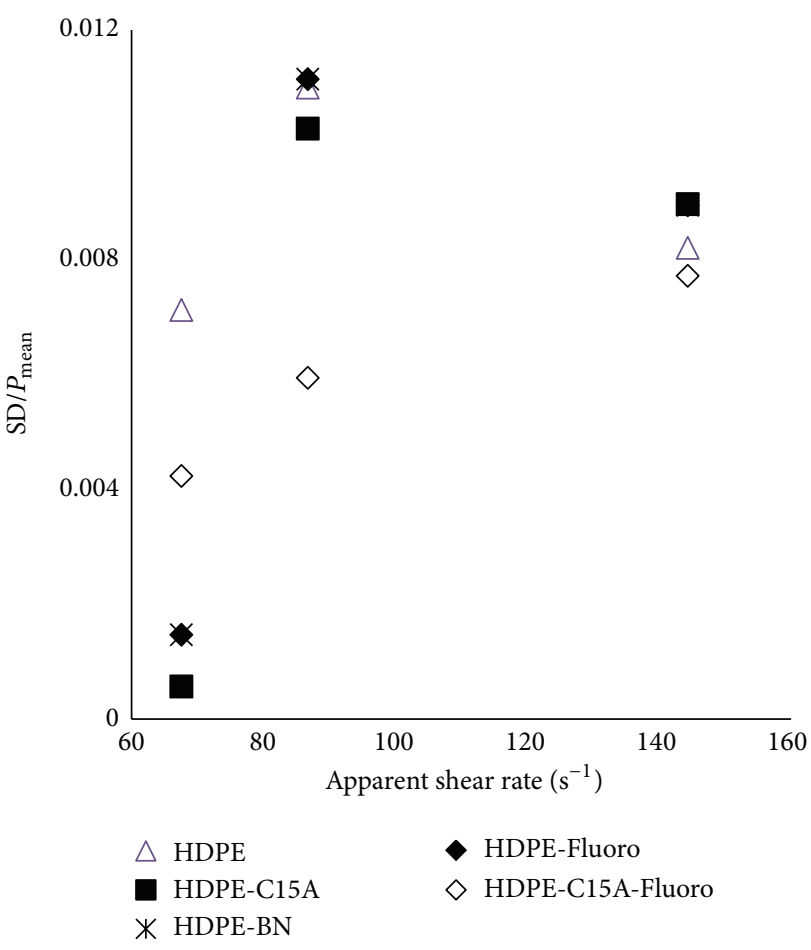

(a)

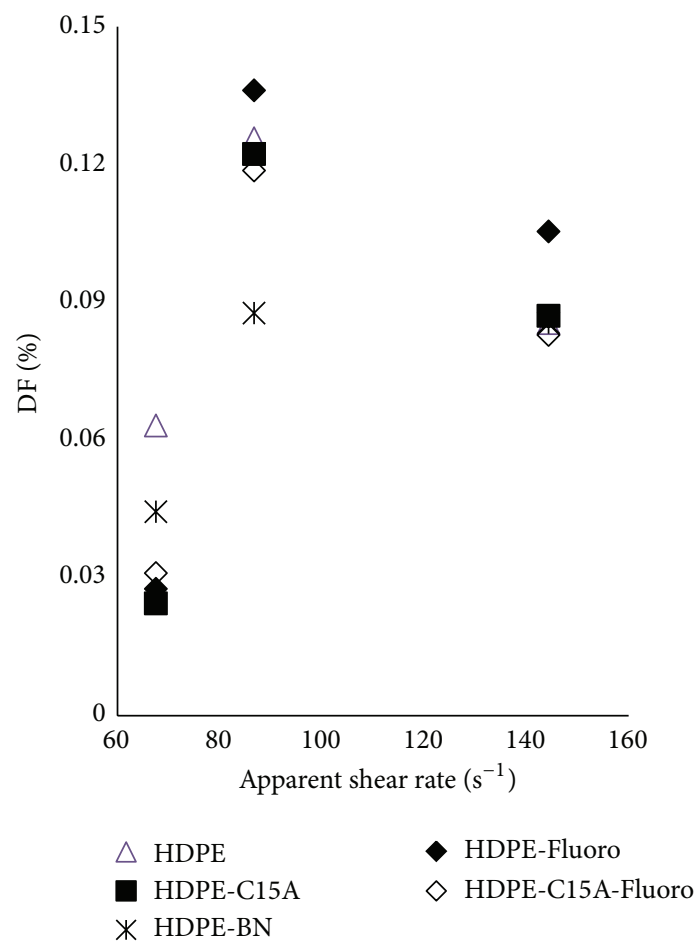

(b)

FIGURE 11: (a) Ratio of standard deviation and the mean pressure. (b) Distortion factor as a function of apparent shear rate for HDPE, HDPEC15A, HDPE-BN, HDPE-Fluoro, and HDPE-C15A-Fluoro at transducer 1 position.

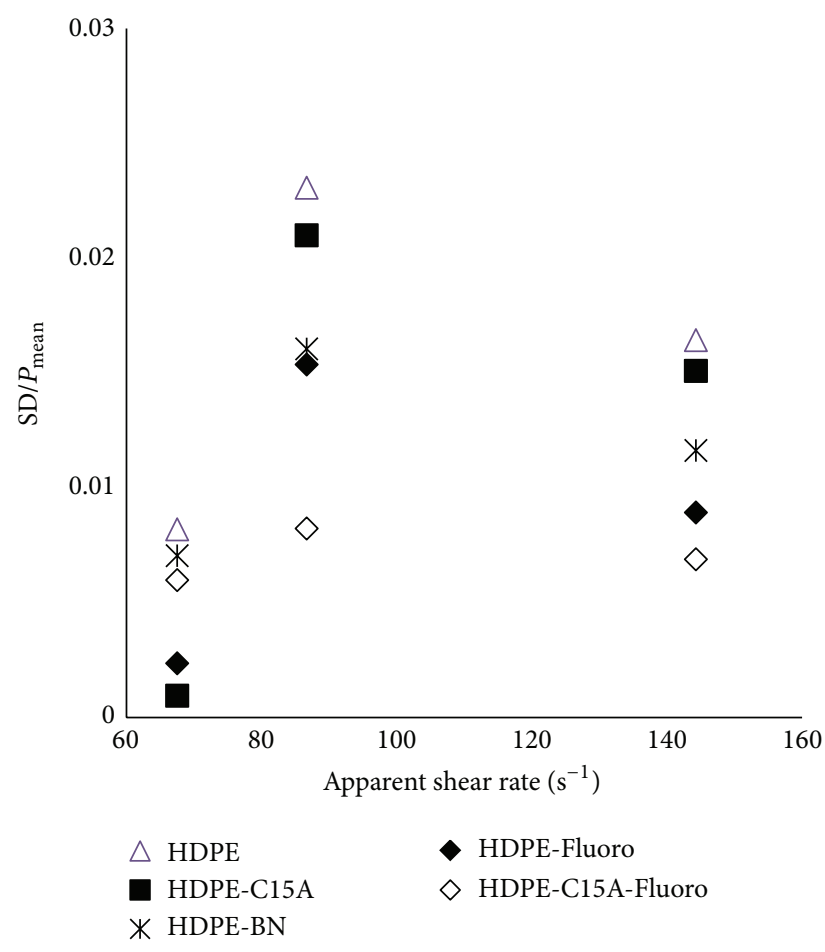

(a)

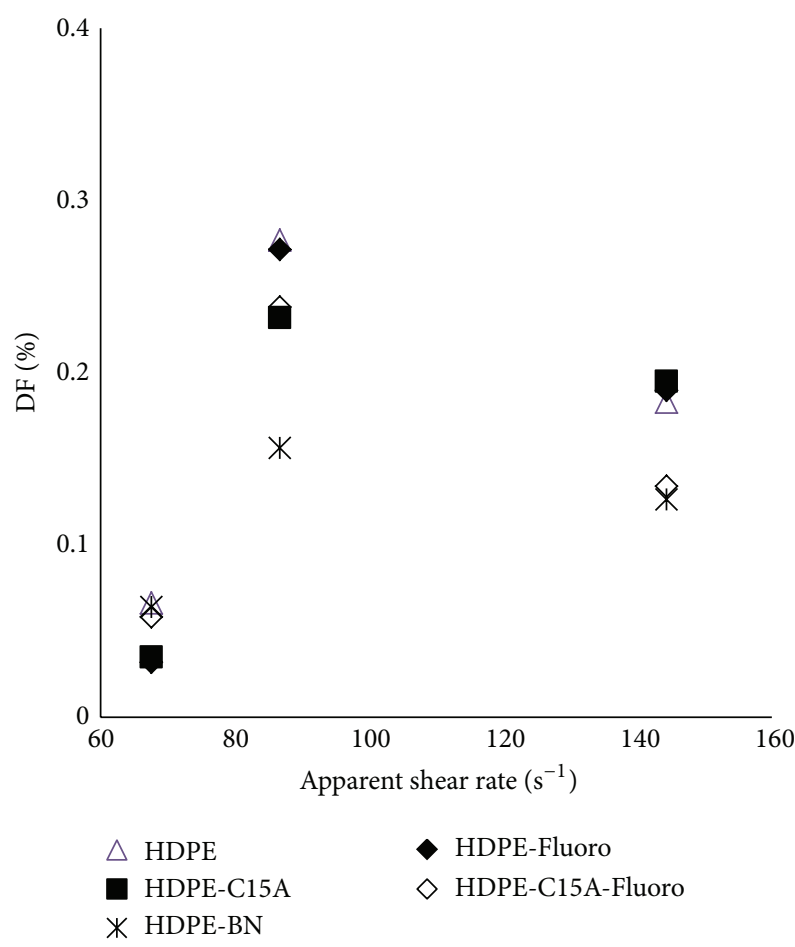

(b)

FIGURE 12: (a) Ratio of standard deviation and the mean pressure. (b) Distortion factor as a function of apparent shear rate for HDPE, HDPEC15A, HDPE-BN, HDPE-Fluoro, and HDPE-C15A-Fluoro at transducer 2 position. 


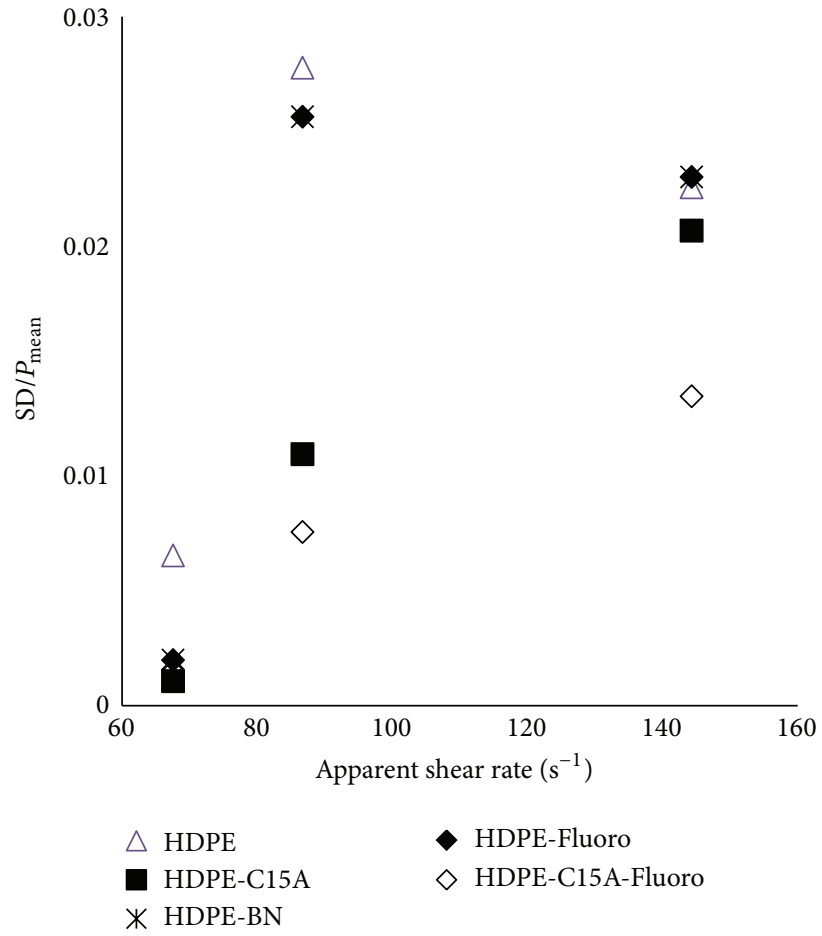

(a)

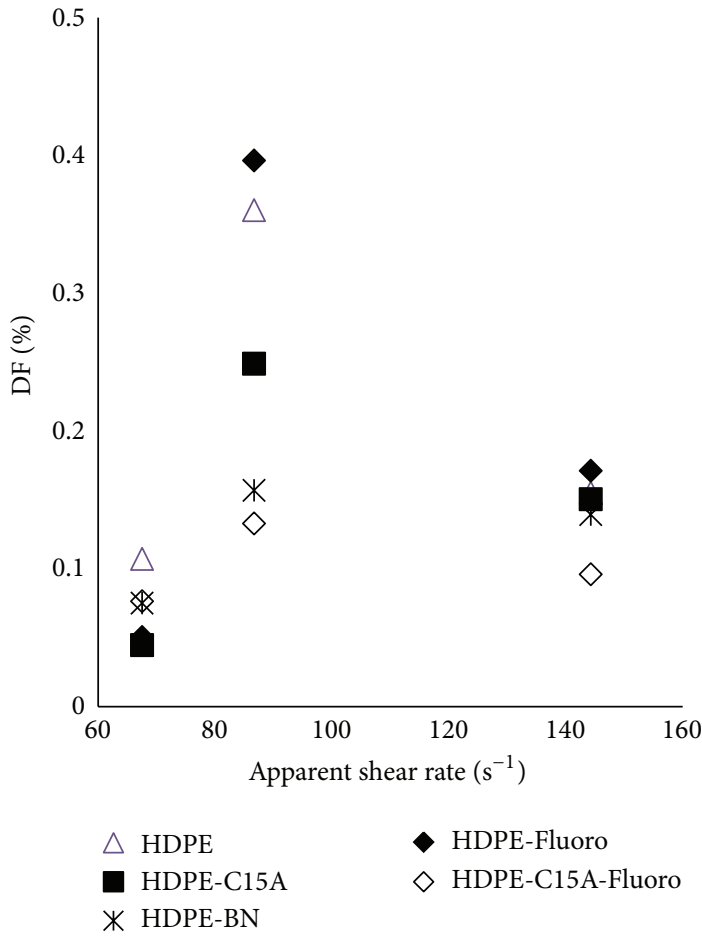

(b)

FIGURE 13: (a) Ratio of standard deviation and the mean pressure. (b) Distortion factor as a function of apparent shear rate for HDPE, HDPEC15A, HDPE-BN, HDPE-Fluoro, and HDPE-C15A-Fluoro at transducer 3 position.

roughness in the HDPE became smooth with the addition of such additives. The results also showed that the stick-slip fracture was eliminated by all processing additives except fluoropolymer. The concentration of fluoropolymer used in this work was probably not optimal for this polymer. Furthermore, boron nitride, organoclay, and the combined organoclay and fluoropolymer did not eliminate the grossmelt fracture at apparent shear rate of $141 \mathrm{~s}^{-1}$. However, both moment and distortion factor methods of analyses were able to quantify the visual trends observed in the extrudates. These methods of analyses indicated that the combined organoclay and fluoropolymer showed the best performance as processing aid and reduced the pressure fluctuation as compared to the performance of individual additives. The industry usually uses these additives in ppm level and in this study we followed the same procedure trying to keep the same weight percentage rather than the same volume percentage. The authors suggest that the observed differences in the performance of the different additives are not likely due to the differences in volume fractions but rather the type and shape of these additives. However, further research is needed to examine the mechanisms in detail.

\section{Conflict of Interests}

The authors declare that there is no conflict of interests regarding the publication of this paper.

\section{Acknowledgments}

The authors are grateful to King Abdul Aziz City for Science and Technology (KACST) for providing financial support for this research under research Grant no. AT-27-107. They also acknowledge the support of King Fahd University of Petroleum and Minerals (KFUPM).

\section{References}

[1] R. G. Larson, "Instabilities in viscoelastic flows," Rheologica Acta, vol. 31, no. 3, pp. 213-263, 1992.

[2] S. Arayachukiat, M. Siriprumpoonthum, S. Nobukawa, and M. Yamaguchi, "Viscoelastic properties and extrusion processability of poly(vinyl butyral)," Journal of Applied Polymer Science, vol. 131, no. 11, 2014.

[3] P. Prateeprat, K. Suchiva, and C. Sirisinha, "Study of rheological behavior and extrudate surface quality of rubber compounds," Advanced Materials Research, vol. 844, pp. 144-148, 2014.

[4] G.-C. Tzeng and R.-H. Chen, "On flow layer uniformity in the co-extrusion of polymer multilayer film," Advanced Materials Research, vol. 939, pp. 381-387, 2014.

[5] E. C. Achilleos, G. Georgiou, and S. G. Hatzikiriakos, "Role of processing aids in the extrusion of molten polymers," Journal of Vinyl and Additive Technology, vol. 8, no. 1, pp. 7-24, 2002.

[6] S. H. Anastasiadis and S. G. Hatzikiriakos, "The work of adhesion of polymer/wall interfaces and its association with the 
onset of wall slip," Journal of Rheology, vol. 42, no. 4, pp. 795-812, 1998.

[7] T. J. Guadarrama-Medina, J. Pérez-González, and L. de Vargas, "Enhanced melt strength and stretching of linear low-density polyethylene extruded under strong slip conditions," Rheologica Acta, vol. 44, no. 3, pp. 278-286, 2005.

[8] S. G. Hatzikiriakos, P. Hong, W. Ho, and C. W. Stewart, "The effect of teflon coatings in polyethylene capillary extrusion," Journal of Applied Polymer Science, vol. 55, no. 4, pp. 595-603, 1995.

[9] I. B. Kazatchkov, S. G. Hatzikiriakos, and C. W. Stewart, "Extrude distortion in the capillary/slit extrusion of a molten polypropylene," Polymer Engineering \& Science, vol. 35, no. 23, pp. 1864-1871, 1995.

[10] S. B. Kharchenko, P. M. McGuiggan, and K. B. Migler, "Flow induced coating of fluoropolymer additives: development of frustrated total internal reflection imaging," Journal of Rheology, vol. 47, no. 6, pp. 1523-1545, 2003.

[11] K. B. Migler, C. Lavallée, M. P. Dillon, S. S. Woods, and C. L. Gettinger, "Visualizing the elimination of sharkskin through fluoropolymer additives: coating and polymer-polymer slippage," Journal of Rheology, vol. 45, no. 2, pp. 565-581, 2001.

[12] F. Rodríguez-González, J. Pérez-González, L. de Vargas, and B. M. Marín-Santibáñez, "Rheo-PIV analysis of the slip flow of a metallocene linear low-density polyethylene melt," Rheologica Acta, vol. 49, no. 2, pp. 145-154, 2010.

[13] K. C. Xing and H. P. Schreiber, "Fluoropolymers and their effect on processing linear low-density polyethylene," Polymer Engineering \& Science, vol. 36, no. 3, pp. 387-393, 1996.

[14] S. R. Oriani, "Optimizing process aid performance by controlling fluoropolymer particle size," Journal of Plastic Film and Sheeting, vol. 21, no. 3, pp. 179-198, 2005.

[15] S. G. Hatzikiriakos, I. B. Kazatchkov, and D. Vlassopoulos, "Interfacial phenomena in the capillary extrusion of metallocene polyethylenes," Journal of Rheology, vol. 41, no. 6, pp. 1299-1316, 1997.

[16] Y. Hong, J. J. Cooper-White, M. E. Mackay, C. J. Hawker, E. Malmström, and N. Rehnberg, "A novel processing aid for polymer extrusion: Rheology and processing of polyethylene and hyperbranched polymer blends," Journal of Rheology, vol. 43, no. 3, pp. 781-793, 1999.

[17] Y. Hong, S. J. Coombs, J. J. Cooper-White et al., "Film blowing of linear low-density polyethylene blended with a novel hyperbranched polymer processing aid," Polymer, vol. 41, no. 21, pp. 7705-7713, 2000.

[18] C. K. Shih, "Rheological properties of incompatible blends of two elastomers," Polymer Engineering \& Science, vol. 16, no. 11, pp. 742-746, 1976.

[19] M. Fujiyama and Y. Kawasaki, "Rheological properties of polypropylene/high-density polyethylene blend melts. I. Capillary flow properties," Journal of Applied Polymer Science, vol. 42, no. 2, pp. 467-480, 1991.

[20] E. E. Rosenbaum, S. K. Randa, S. G. Hatzikiriakos, C. W. Stewart, D. L. Henry, and M. Buckmaster, "Boron nitride as a processing aid for the extrusion of polyolefins and fluoropolymers," Polymer Engineering and Science, vol. 40, no. 1, pp. 179190, 2000.

[21] I. B. Kazatchkov, F. Yip, and S. G. Hatzikiriakos, "The effect of boron nitride on the rheology and processing of polyolefins," Rheologica Acta, vol. 39, no. 6, pp. 583-594, 2000.
[22] N. S. Rathod and S. G. Hatzikiriakos, "The effect of surface energy of boron nitride on polymer processability," in Proceedings of the 61st Annual Technical Conference (ANTEC '03), pp. 17-21, May 2003.

[23] S. G. Hatzikiriakos, N. Rathod, and E. B. Muliawan, "The effect of nanoclays on the processibility of polyolefins," Polymer Engineering \& Science, vol. 45, no. 8, pp. 1098-1107, 2005.

[24] S. Boufassa, R. Doufnoune, A. Hellati, N. Haddaoui, and M. E. Cagiao, "Effect of compatibilizing agents on the physical properties of iPP/HDPE organoclay blends," Journal of Polymer Engineering, vol. 33, no. 7, pp. 589-598, 2013.

[25] P. Eteläaho, K. Nevalainen, R. Suihkonen, J. Vuorinen, and P. Järvelä, "Effects of two different maleic anhydride-modified adhesion promoters (PP-g-MA) on the structure and mechanical properties of nanofilled polyolefins," Journal of Applied Polymer Science, vol. 114, no. 2, pp. 978-992, 2009.

[26] J. H. Lee, W. J. Kim, H. S. Cho et al., "Effect of clay content and dispersion on the flame retardancy in EVA-based-polyolefin/clay nanocomposites," in Proceedings of the Regional Technical Conference-Society of Plastics Engineers, Technical Papers, pp. 1238-1242, 2008.

[27] R. Nalini, S. Nagarajan, and B. S. R. Reddy, "Polypropyleneblended organoclay nanocomposites-preparation, characterisation and properties," Journal of Experimental Nanoscience, vol. 8, no. 4, pp. 480-492, 2013.

[28] S. G. Hatzikiriakos and K. B. Migler, Polymer Processing Instabilities Control and Understanding, Marcel Dekker, New York, NY, USA, 2005.

[29] C. Dubrocq-Baritaud, E. Darque-Ceretti, and B. Vergnes, "Influence of die surface on the efficiency of fluoropolymer processing aids during the extrusion of linear-low density polyethylene," Journal of Non-Newtonian Fluid Mechanics, vol. 166, no. 14-15, pp. 847-858, 2011.

[30] C. Dubrocq-Baritaud, E. Darque-Ceretti, and B. Vergnes, "Multi-scale phenomena induced by fluoropolymer processing aids during the extrusion of linear-low density polyethylene," Journal of Non-Newtonian Fluid Mechanics, vol. 166, no. 1-2, pp. $1-11,2011$.

[31] S. Neuhaus, C. Padeste, and N. D. Spencer, "Functionalization of fluropolymers and polyolefins via grafting of polyelectrolyte brushes from atmospheric-pressure plasma activated surfaces," Plasma Processes and Polymers, vol. 8, no. 6, pp. 512-522, 2011.

[32] K. B. Migler, Y. Son, F. Qiao, and K. Flynn, "Extensional deformation, cohesive failure, and boundary conditions during sharkskin melt fracture," Journal of Rheology, vol. 46, no. 2, pp. 383-400, 2002.

[33] D. A. Hill, T. Hasegawa, and M. M. Denn, "On the apparent relation between adhesive failure and melt fracture," Journal of Rheology, vol. 34, no. 6, pp. 891-918, 1990.

[34] C. W. Stewart, "Wall slip in the extrusion of linear polyolefins," Journal of Rheology, vol. 37, no. 3, pp. 499-513, 1993.

[35] J. R. Barone, N. Plucktaveesak, and S. Q. Wang, "Interfacial molecular instability mechanism for sharkskin phenomenon in capillary extrusion of linear polyethylenes," Journal of Rheology, vol. 42, no. 4, pp. 813-832, 1998.

[36] D. Bigio, M. G. Meillon, and S. R. Oriani, "Sharkskin elimination: fluoroelastomer coating evolution as a polymer processing aid," in Proceedings of the International Polyolefins Conference (FLEXPACKCON '08), pp. 357-393, Society of Plastics Engineers, 2008. 
[37] F. Yip, S. G. Hatzikiriakos, and T. M. Clere, "A new processing aid for the extrusion of polyolefins," Journal of Vinyl and Additive Technology, vol. 6, no. 2, pp. 113-118, 2000.

[38] K. Yip, E. E. Rozenbaum, S. K. Randa, S. G. Hatzikiriakos, and C. W. Stewart, "The effect of boron nitride type and concentration on the rheology and processability of molten polymers," in Proceedings of the ANTEC, pp. 1223-1227, Society of Plastic Engineers, New York, NY, USA, 1999.

[39] M. Seth, S. G. Hatzikiriakos, and T. M. Clere, "Gross melt fracture elimination: the role of surface energy of boron nitride powders," Polymer Engineering \& Science, vol. 42, no. 4, pp. 743752, 2002

[40] E. A. Pruss, S. K. Randa, S. S. Lyle, and T. M. Clere, "Properties of m-LLDPE blown films extruded utilizing boron nitride based polymer process aids," in Proceedings of the SPE Annual Technical Conference (ANTEC '02), Technical Paper, pp. 2864-2868, Society of Plastic Engineers, San Francisco, Calif, USA, May 2002.

[41] R. Vogel, S. G. Hatzikiriakos, H. Brünig, B. Tändler, and M. Golzar, "Improved spinnability of metallocene polyethylenes by using processing aids," International Polymer Processing, vol. 18, no. 1, pp. 67-73, 2003.

[42] A. A. Adesina and I. A. Hussein, "Impact of organoclay and maleated polyethylene on the rheology and instabilities in the extrusion of high density polyethylene," Journal of Applied Polymer Science, vol. 123, no. 2, pp. 866-878, 2012.

[43] A. A. Adesina, A. A. Al-Juhani, N. Tabet, A. Ul-Hamid, and I. A. Hussein, "Rheology and enhancement of extrusion of linear and branched polyethylenes using low amount of organoclay," Journal of Applied Polymer Science, vol. 126, no. 2, pp. 713-723, 2012.

[44] M. Seth and S. G. Hatzikiriakos, "Combining boron nitride with a fluoroelastomer: an enhanced polymer processing additive," Journal of Vinyl and Additive Technology, vol. 7, no. 2, pp. 90-97, 2001. 

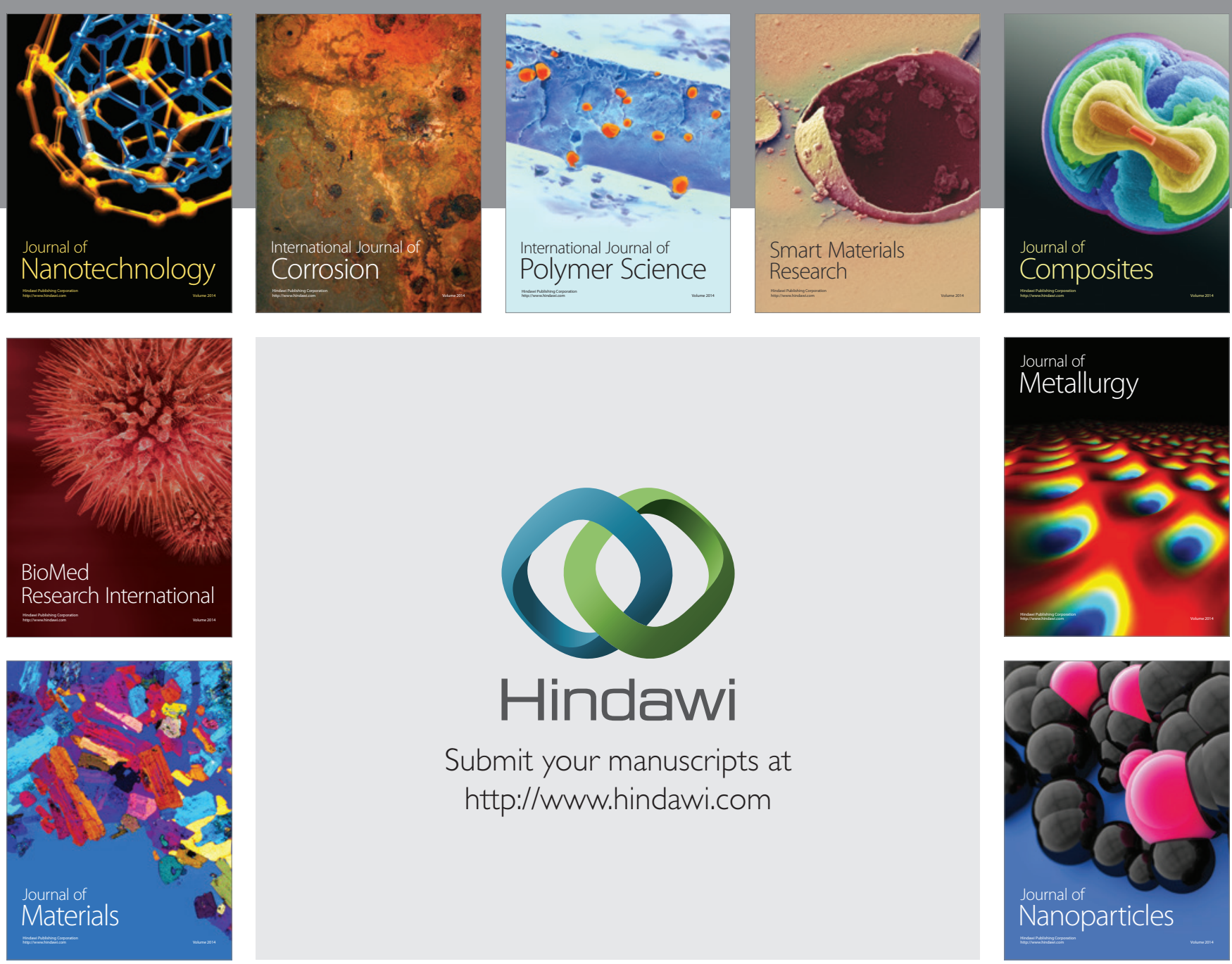

Submit your manuscripts at http://www.hindawi.com
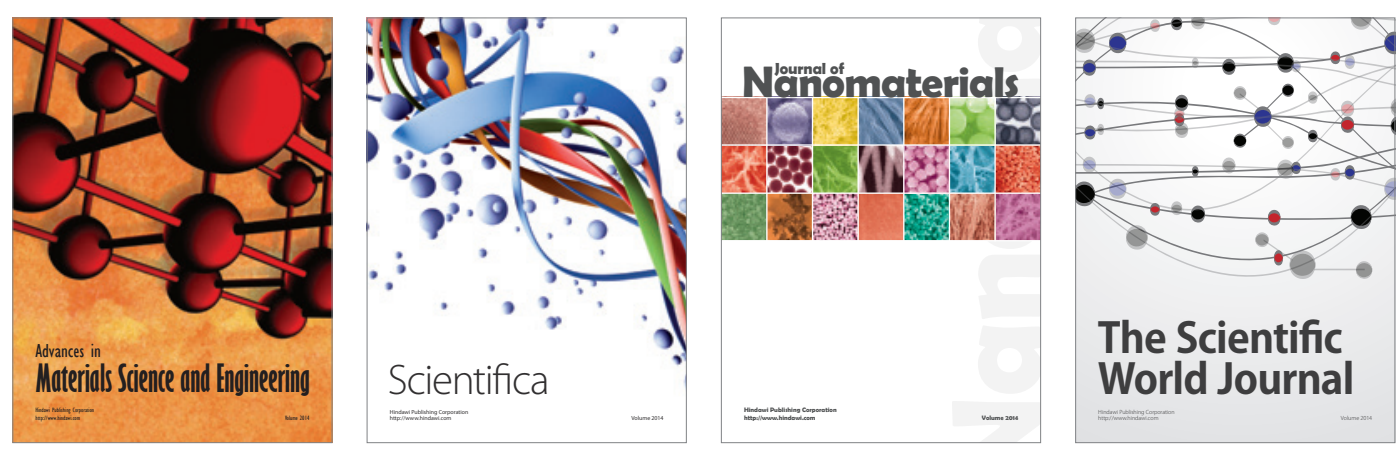

\section{The Scientific World Journal}
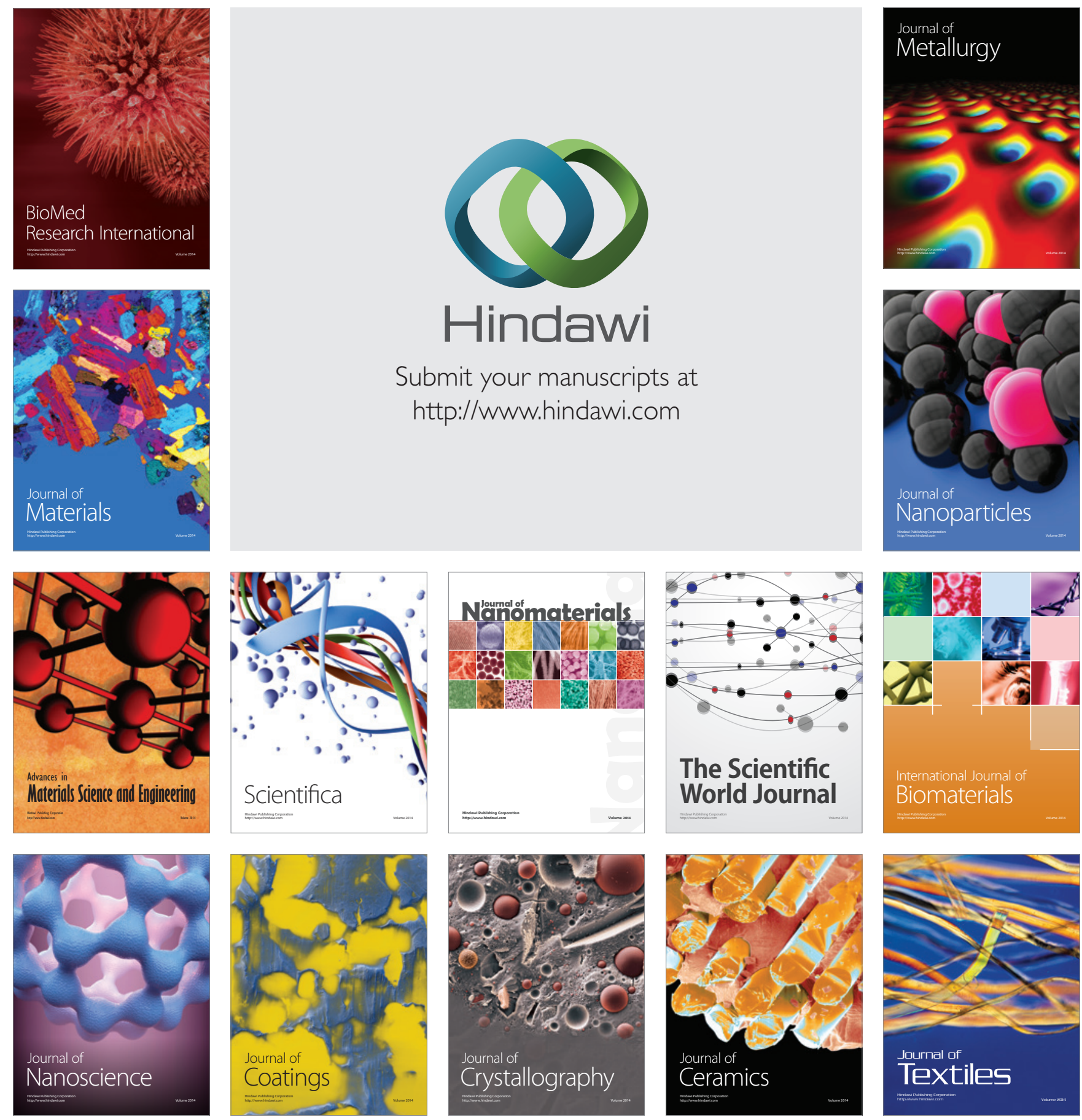